\title{
Histologic-Genetic Mapping by Allele-Specific PCR Reveals Intraurothelial Spread of p53 Mutant Tumor Clones
}

\author{
Robert Stoehr, Ruth Knuechel, Joerg Boecker, Hagen Blaszyk, Ruediger Schmitt, \\ Thomas Filbeck, Ferdinand Hofstaedter, and Arndt Hartmann
}

Institute of Pathology (R. Stoehr, RK, JB, $H B, F H, A H)$ and Department of Genetics (R. Schmitt), University of Regensburg, and Department of Urology (TF), St. Josef-Hospital, Regensburg, Germany

SUMMARY: Common and clinically important features of urothelial carcinomas are multifocality and a high rate of recurrence. Molecular studies demonstrated that multifocal tumors are frequently composed of one tumor clone spreading throughout the urothelial tract. A combination of histologic and genetic mapping of cystectomy specimens from bladder cancer patients is a valuable tool to study bladder carcinogenesis and tumor cell spread by correlating urothelial morphologic features and defined genetic alterations. In the present study, the primary tumors of 14 cystectomy specimens were investigated for p53 protein overexpression by immunohistochemistry and p53 gene mutation by genomic sequencing. Seven tumors showed a strong nuclear staining for the p53 protein. In six of seven tumors, a p53 gene mutation was detected. Allele-specific PCR of defined p53 mutations was established in five of six cases with a p53 mutation. Subsequent screening of the entire urothelial lining of each cystectomy specimen by allele-specific PCR revealed p53-mutant cell clones in urothelial patches with carcinoma in situ and dysplasia, but also frequently in histomorphologically normal urothelium adjacent to the tumor. The pattern of tumor cell spread indicated a continuous intraurothelial growth of the p53-mutant clone. P53 immunohistochemistry visually confirmed the presence of mutant cells in most of these samples. We conclude that allele-specific PCR is a highly sensitive and reliable method for tracking specific p53 mutant clones in the urothelium. Moreover, the detection of p53-mutant cells in histologically normal or preneoplastic urothelial areas in four patients with invasive bladder cancer indicates an extensive intraurothelial tumor cell spread. The excellent correlation of immunohistochemically positive urothelial patches with the presence of a specific mutation highlights the biologic significance of p53-positive cells in the urothelium of tumor patients. (Lab Invest 2002, 82:1553-1561).

O ne of the clinically most important features of urothelial cancer is the frequent multifocality and a very high rate of recurrence (Dalbagni et al, 2001). An understanding of the underlying mechanisms of the multifocality of urothelial carcinomas is required to design appropriate strategies for early detection and treatment. Histopathologically, two different types of urothelial carcinoma can be found: (1) mostly superficial, papillary tumors $(80 \%)$ with high rates of recurrence but only a low tendency for progression to invasive disease, and (2) highly malignant, invasive solid tumors $(20 \%)$ with a poor prognosis for the patient. Cancer of the urothelium appears to evolve through two genetic pathways (reviewed in CordonCardo et al, 2000). Deletions of several regions of both arms of chromosome 9 are a very early and frequent event in the development of papillary tumors (Simo-

\section{DOI: 10.1097/01.LAB.0000035022.29742.85}

Received July 23, 2002.

Grant number and support name: 10-1598/HA 2 (Dr. Mildred ScheelStiftung for Cancer Research); Kn 263/7-2 (German Research Foundation $D F G$ ).

Address reprint requests to: Dr. Arndt Hartmann, Institute of Pathology, University of Regensburg, Franz-Josef-Strauss-Allee 11, 93042 Regensburg, Germany. E-mail:arndt.hartmann@klinik.uni-regensburg.de neau et al, 1999). Such deletions can already be detected in early preneoplastic lesions like flat and papillary urothelial hyperplasias and in normal urothelium of cancer patients (Chow et al, 2000; Czerniak et al, 1999; Hartmann et al, 1999). In contrast, solid invasive tumors frequently show deletions of chromosome $17 p$ and mutations of the p53 gene, changes that can already be found in dysplasia or carcinoma in situ (CIS) (Hartmann et al, 2002; Spruck et al, 1994; Stoehr et al, 2000).

Multifocality and recurrence raise the question of the clonal nature of spatially distinct urothelial tumors, and two models have been proposed: (1) The monoclonality hypothesis defines tumors as descendants of a single transformed cell, which proliferates and spreads throughout the urothelial lining by either intraluminal seeding or intraepithelial migration. Tumor cells might detach from the primary lesion and seed in the urine with secondary implantation at different sites. Alternatively, malignant cells are thought to migrate continuously throughout the epithelium (Harris and Neal, 1992). (2) The field cancerization model postulating multiple independent mutation events was originally applied to multifocal oral squamous cell carcinoma (Slaughter et al, 1953). In urothelial carcinoma, carcinogens may exclusively affect the urothe- 
lium at multiple sites, leading to independent multifocal tumors.

Both hypotheses have been supported by molecular studies. Multifocal advanced tumors show monoclonal disease in most cases (Habuchi et al, 1993; Sidransky et al, 1992), but investigation of early papillary tumors and preneoplastic lesions also revealed tumor clones with different genetic alterations in some cases (Hafner et al, 2001; Hartmann et al, 1999, 2002; Paiss et al, 2002; Spruck et al, 1994; Stoehr et al, 2000).

Simon et al (2001) proposed a model of intraepithelial migration of a mutant tumor clone, based on comparative genome hybridization $(\mathrm{CGH})$ studies of invasive bladder cancer. Other authors found genetically altered cell clones in the "urothelial field" of bladder cancer patients as the origin of recurrent tumors. Muto et al (2000) examined deletions at several chromosomal regions (loss of heterozygosity, $\mathrm{LOH})$ and methylation of the p16 gene in normal bladder epithelium in patients with metachronous bladder cancer. Alterations were found in more than $75 \%$ of the samples from patients with bladder cancer, but not in samples from control patients. In contrast, Baud et al (1998) investigated normal bladder mucosa samples from patients with prostate pathology and found a frequent $\mathrm{LOH}$ at chromosome 9p, especially LOH at the microsatellite marker D9S156. We previously reported chromosome 9 deletions in urothelial hyperplasia and normal urothelium of patients with bladder cancer (Hartmann et al, 1999), frequent deletions at chromosomes 9 and 17, as well as p53 mutations in dysplastic urothelial lesions (Hartmann et al, 2002).

Koss (1979) first described histologic mapping of the entire urothelial lining in patients with bladder cancer. Based on this work, Chaturvedi et al (1997), Czerniak et al (1999, 2000), Kram et al (2001), and Yoon et al (2001) performed histologic-genetic mapping of cystectomy specimens with invasive tumors by $\mathrm{LOH}$ analysis of chromosomes 5, 9, 16, and 17 . Subsequently, a model for urothelial carcinogenesis emerged (Czerniak et al, 2000), but questions of clonality and mechanisms of tumor spread remained unanswered.

P53-gene mutations are found in approximately $50 \%$ of urothelial carcinomas (Cordon-Cardo et al, 2000) of the urinary bladder that are already present in early dysplasia (Hartmann et al, 2002). The presence of numerous different p53 mutations in various cancers (Hainaut and Hollstein, 2000) makes the p53 gene an ideal tool for clonality analyses, because it is unlikely that several tumors from a patient with an identical p53 mutation are of polyclonal origin. Genomic sequence analysis of p53-mutations is limited by its sensitivity. A fraction of at least $30 \%$ of mutated cells is needed to reliably detect a mutation. A much more sensitive method for the detection of known mutations is the PCR amplification of specific alleles (PASA) (Bottema and Sommer, 1993), facilitating detection of a small number of mutated cells within a given cell population. In this study we used the combination of histologic urothelial mapping, p53 immunohistochemistry, genomic sequencing, and PASA to determine the distribution of a tumor clone within the urinary bladder in patients with invasive urothelial carcinoma.

\section{Results}

\section{Immunohistochemistry (IHC) and Sequencing of p53}

Tumor samples from all 14 cystectomies were successfully analyzed by IHC. Seven tumors without p53 staining had also a negative mutation analysis of exons 5 to 9. Seven tumors showed strong nuclear staining of the p53 protein (Fig. 3a) and genomic sequencing revealed p53-mutations in six tumors (Table 1). One of the tumors with nuclear p53 staining showed a mutation (exon 8 , codon 281), but this result could not be confirmed in independent analyses. Thus, eight cystectomy specimens with wild-type p53 tumors were not used in this study.

\section{PASA}

Specific PASA analysis could be performed in five of six patients with mutations. In Patient 6, no specific PASA reaction for the mutation (exon 8 , codon 280 : $A G A \rightarrow A C A$ ) could be established and was therefore not used for analysis. The sensitivity of PASA was determined by using tumor DNA from Patient 1 in different dilutions with DNA from the urothelial cell line UROtsa. Figure 1B shows that the mutated p53 allele could be detected by PASA in a 1:50 dilution of tumor DNA.

Overall, 140 tissue samples (82 normal urothelium, 14 hyperplasia, 10 dysplasia, 10 squamous metaplasia, $13 \mathrm{CIS}$, and 11 urothelial carcinoma) from the five cystectomies were analyzed. Clinical and pathologic characteristics are shown in Table 2 . The exact location of all investigated samples, the histologic classification and the results of the PASA analyses of each lesion are shown in Figures 1 and 2. In four cystectomies (Patients 1, 2, 4, and 5) the specific p53-mutation could be detected in preneoplastic lesions (hyperplasia, dysplasia) and normal urothelium. All urothelial samples with mutation were in proximity to the tumor. In Patient 3, the p53-mutation was detected only in the tumor sample. There was no correlation between the spread of a mutant cell clone and the histopathologic features of the primary tumor.

\section{p53 IHC}

IHC staining for expression of p53 was successful in four of the five cystectomies (Patients 1, 3, 4, and 5). Not all samples investigated by PASA showed sufficient urothelium for interpretable $\mathrm{IHC}$ in serial sections. It was, however, possible to assess nuclear p53 expression in 103 of 119 samples.

There was good correlation between p53 IHC positivity and the PASA reaction. Overall, in 84 of the 103 samples, the results of PASA have been confirmed by IHC (Fig. 3). Six urothelial samples 


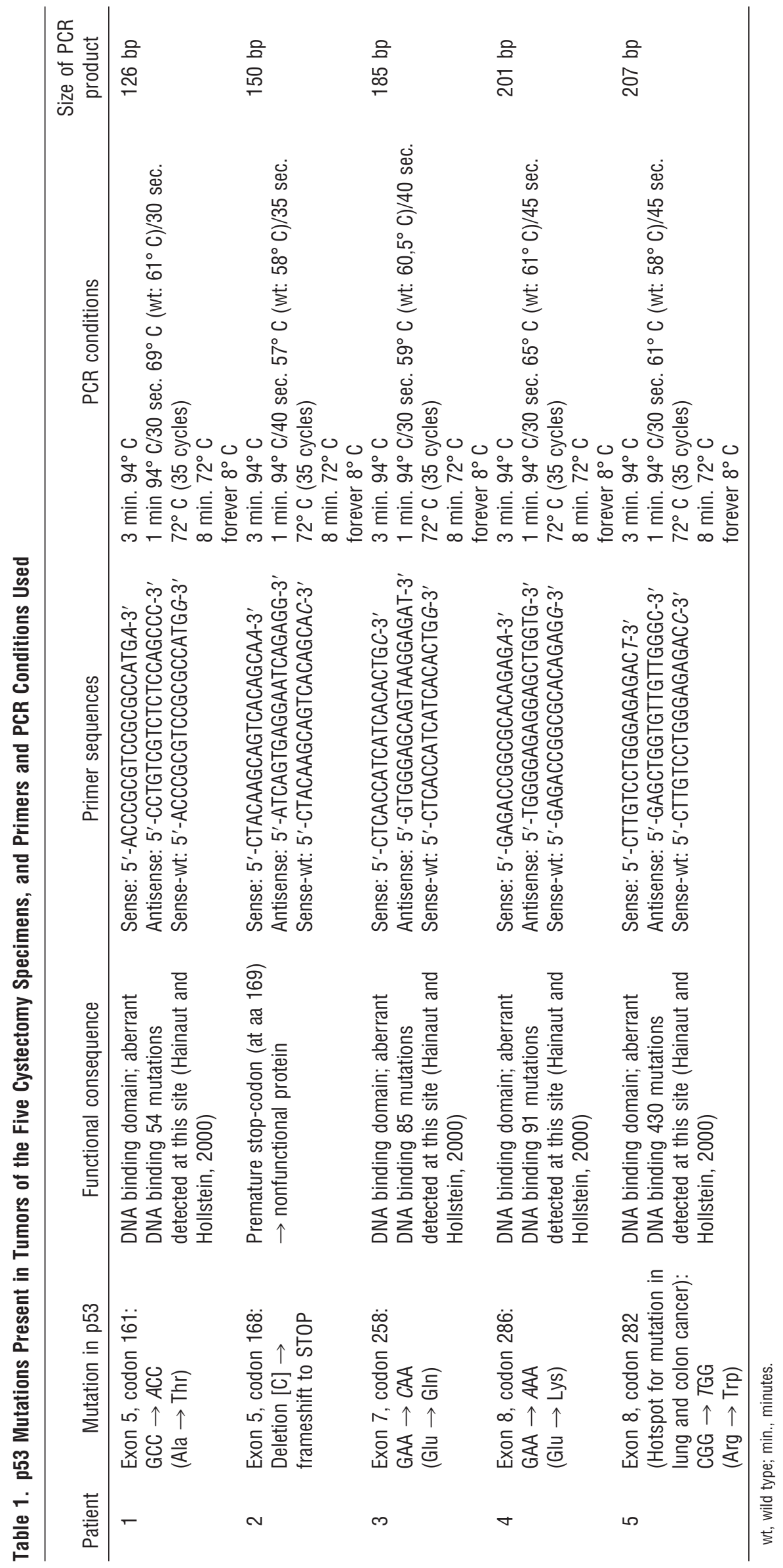




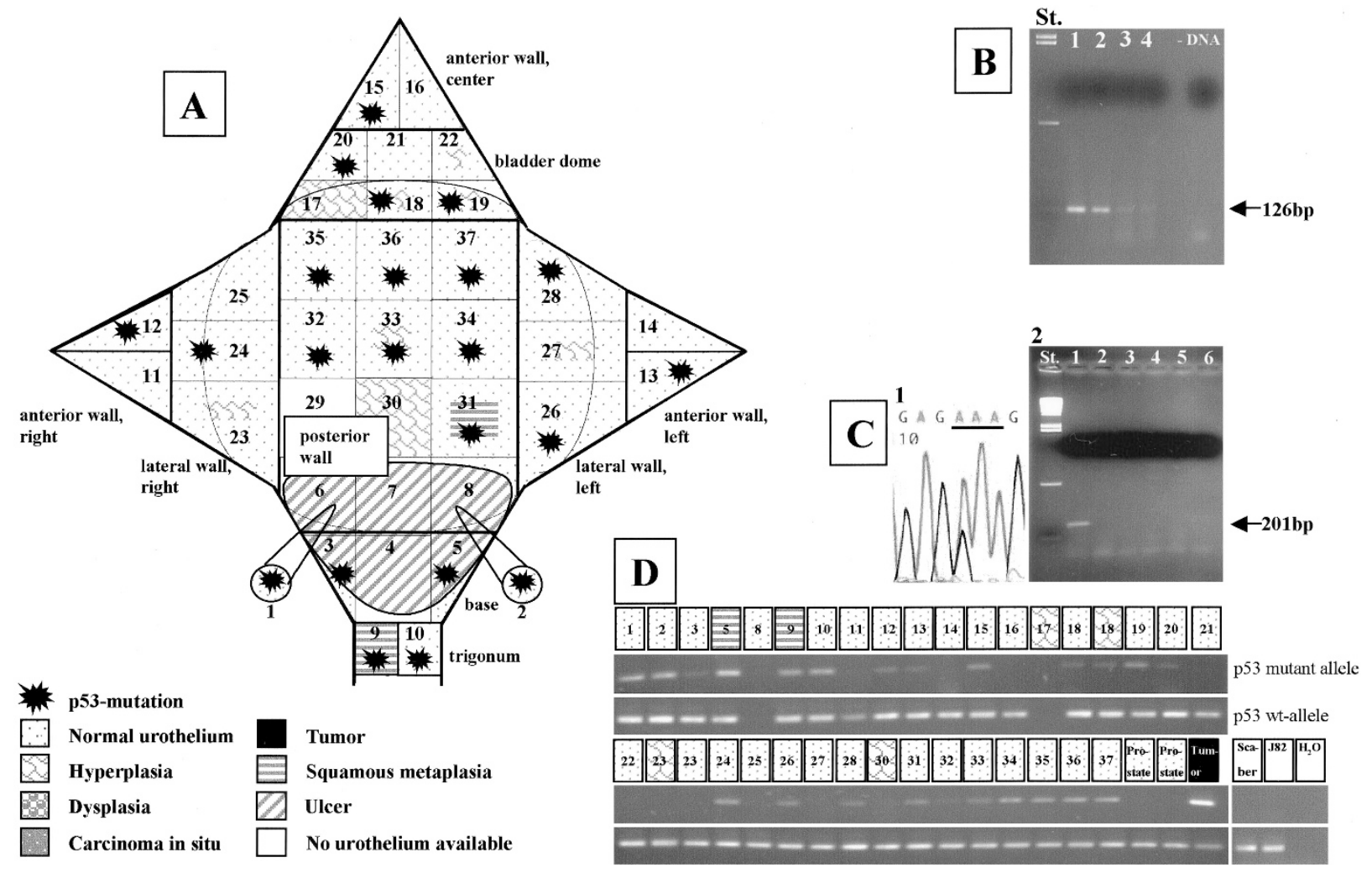

Figure 1.

Histopathology and allele-specific PCR (PASA) of the urothelium of Patient 4. A, Map of cystectomy specimen 4 opened by an Y-section. Location and histopathologic diagnosis of the analyzed samples are summarized and samples with p53 mutation are highlighted $\left({ }^{\star}\right)$. Spread of tumor cells containing the p53 mutation within the urothelium is visible. B, PASA using UROtsa DNA (wild-type) spiked with tumor DNA containing a specific p53 mutation (Patient 1; Table 1). The UROtsa cell line was isolated from a primary culture of normal human urothelium through immortalization with a construct containing the SV40 large T antigen. The cell line has a diploid karyotype and can be used as a cell culture model of normal human urothelium (Rossi et al, 2001). No p53 mutations can be found in this cell line. UROtsa was used as a normal control in several studies investigating genetic alterations in urothelial lesions using fluorescence in situ hybridization analysis (FISH) including the p53 locus (Hartmann et al, 1999, 2002). Ratio of mutated p53 to wild-type DNA: Lane 1, 1:0; Lane 2, 1:10; Lane 3, 1:20, Lane 4, 1:50. The arrow marks the 126-bp mutant band. C1, Partial sequence of p53 from the primary tumor of Patient 4 exhibiting a GAA to AAA mutation in codon 286 (Table 1). C2, Specificity of PASA for the p53 mutation. Lane 1, tumor DNA; Lane 2, UROtsa DNA; Lane 3, RT112 DNA; Lane 4, Scaber DNA; Lane 5, J82 DNA; Lane 6, $\mathrm{H}_{2} \mathrm{O}$. All cell lines without the described p53 mutations (Table 1). D, PASA screening of the entire cystectomy specimen for the tumor-specific p53 mutation. Histologic diagnosis of samples is symbolized as in A. PASA bands of the corresponding DNAs (100 ng/ $\mu$ l; upper lanes). p53 mutation and PCR product can be found in several samples of normal and preneoplastic urothelium. The lower lane shows PASA for wild-type p53. The presence of a PCR product indicates a sufficient amount and quality of the DNA for analysis.

Table 2. Clinical and Pathological Characteristics of Five Patients Investigated by Allele-Specific PCR

\begin{tabular}{cllcc}
\hline Patient & \multicolumn{1}{c}{ Age/sex } & Max. diagnosis & Growth pattern & $\begin{array}{c}\text { Concomitant flat } \\
\text { urothelial lesion }\end{array}$ \\
\hline 1 & 66 years/woman & pT1G2pTaG1 & Papillary & - \\
2 & 66 years/man & pT2aG3 & Solid & Dysplasia \\
& & pT1G3 & Multifocal CIS \\
3 & 64 years/man & pT1G3 & Papillary & Dysplasia \\
4 & 70 years/man & pT2aG3 & Solid & - \\
5 & 60 years/woman & pT3aG3 & Solid & Dysplasia \\
& & & & Multifocal CIS \\
\hline
\end{tabular}

showed positive IHC staining and negative PASA, whereas nuclear p53 accumulation was not seen in 13 samples with positive PASA. Most PASA-positive samples showed nuclear p53 staining in $5 \%$ to $20 \%$ of the cells. Surface urothelial cells with slight nuclear irregularity frequently showed positive staining (Fig. 3, C to E).

\section{Discussion}

The mechanisms by which multifocal bladder tumors develop are controversial. There is experimental evidence for both monoclonal spread of one tumor cell clone and oligoclonal tumor development as a result of a field defect (Hafner et al, 2001; Paiss et al, 2002; 

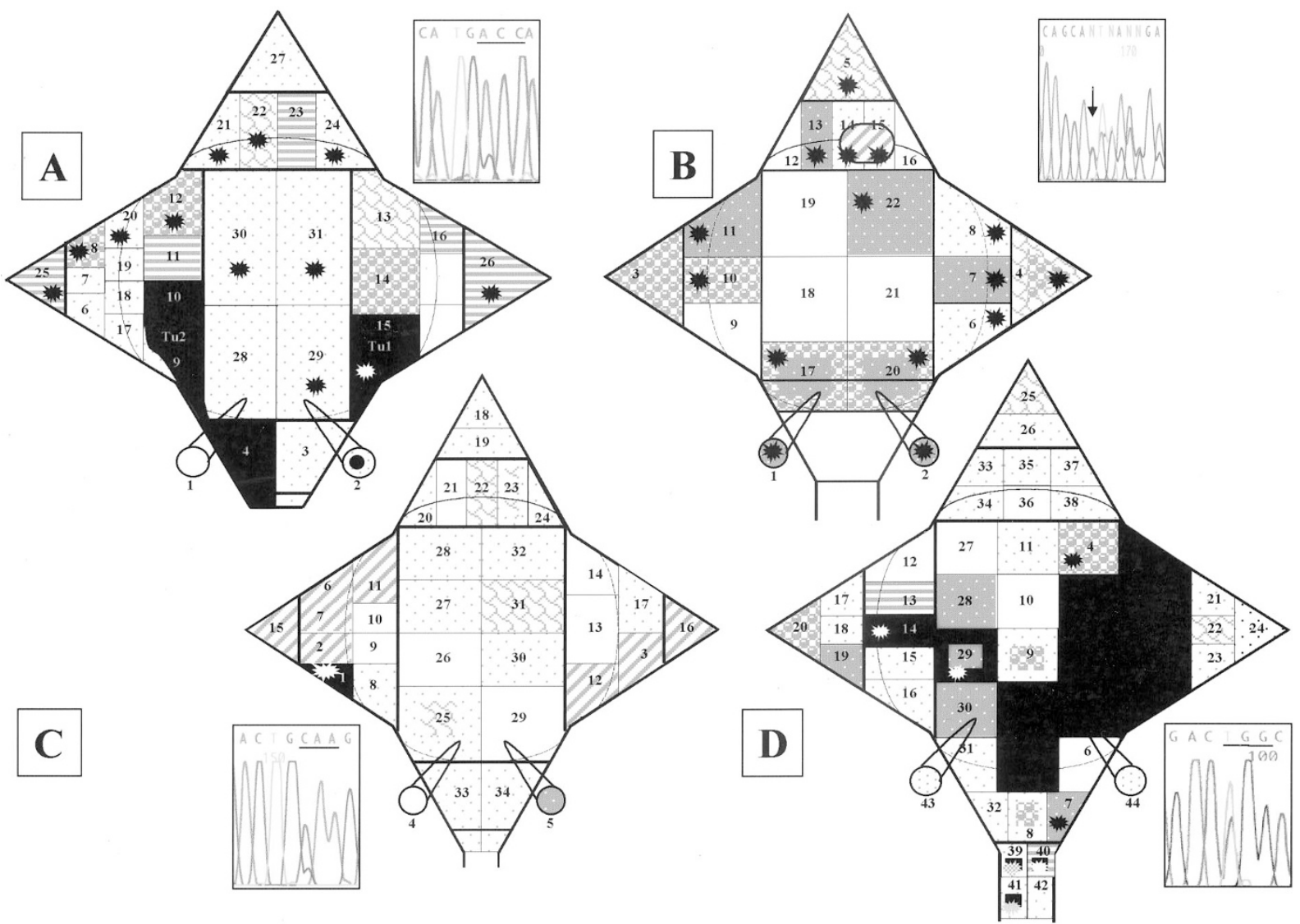

Figure 2.

Histologic maps, p53 PASA diagnoses $\left(^{\star}\right)$, and p53 mutation of the patients. Graphical display of the histologic grading as in Figure 1A. A, Cystectomy specimen of Patient 1. Two separate tumors were found in the left (tumor 1) and the right (tumor 2) bladder wall. Only tumor 1 contained a p53 mutation with spread of p53-mutant tumor cells. B, Cystectomy specimen of Patient 2 showing multifocal carcinoma in situ with clonal spread of the mutant cells. The arrow in the sequence pattern indicate deletion of a cytosin residue (Table 1). C, Cystectomy specimen of Patient 3. The p53 mutation was only detectable in the tumor. None of the other analyzed tissue samples showed the p53 mutation-specific PASA product. D, Cystectomy specimen of Patient 5. Limited spread of tumor cells. A p53 mutation-specific PASA product was only detectable in samples adjacent to the tumor.

Simon et al, 2001; Takahashi et al, 2001). Intraluminal seeding and intraepithelial migration are major mechanisms currently considered.

In this study, histologic-genetic mapping of cystectomy specimens defined the spread of five tumor clones with a distinct p53 mutation throughout the urothelial lining. A p53 mutation of the invasive tumor was also detected in patches of preneoplastic lesions and normal urothelium of the same bladder. PASA analyses had high sensitivity and detected $5 \%$ mutant cells in a background of normal cells. Surprisingly, p53 mutant clones were detectable in several areas of histologically inconspicuous normal urothelium.

All cystectomies were also assessed for $\mathrm{LOH}$ at the p53 locus (data not shown). Three patients (Patients 3, 4 , and 5) were noninformative (homozygous) for several markers on chromosome 17p13.1. The tumors of Patients 1 and 2 showed an $\mathrm{LOH}$ at the p53 locus. In Patient 1 , only tumor 2 showed a chromosomal deletion at the p53 locus but there was no $\mathrm{LOH}$ in tumor 1 . The $\mathrm{LOH}$ analysis of all tissue samples from Patient 1 showed no deletion of the p53 locus in any other nontumor tissue sample. In both patients, $\mathrm{LOH}$ could not be detected in nontumor lesions. This could be explained by the fact that the cells with mutant p53 and presumable loss of the second allele detected in urothelial patches by PASA were outnumbered by normal urothelial cells. An amount of at least $60 \%$ to $75 \%$ of cells containing a deletion is necessary to reliably detect LOH (Boelker, 1996). Immunohistochemical data reveal positive staining only in a fraction of the urothelium not reaching the critical level for detection of $\mathrm{LOH}$ (see Fig. 3B).

P53 is a very good "tracking tool" for such studies. There are a few examples of mutational hotspots in the p53 gene induced by specific carcinogens (for review see Harris, 1996), but in bladder cancer no specific carcinogen-induced hotspot has been reported so far (Hainaut et al, 1998). Thus, it is very unlikely that the identical mutation would occur as a de novo event in several urothelial regions from the same patient. The most likely explanation of our data is that cells of the primary tumor have migrated to different regions of the bladder, supported by the excellent correlation of p53 mutation detected by PASA and the patches of p53-positive cells found by IHC. In contrast, routine light microscopy does not 


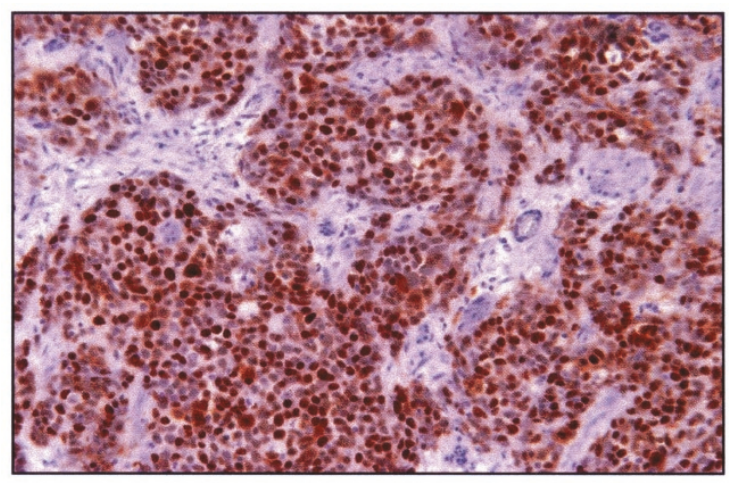

A

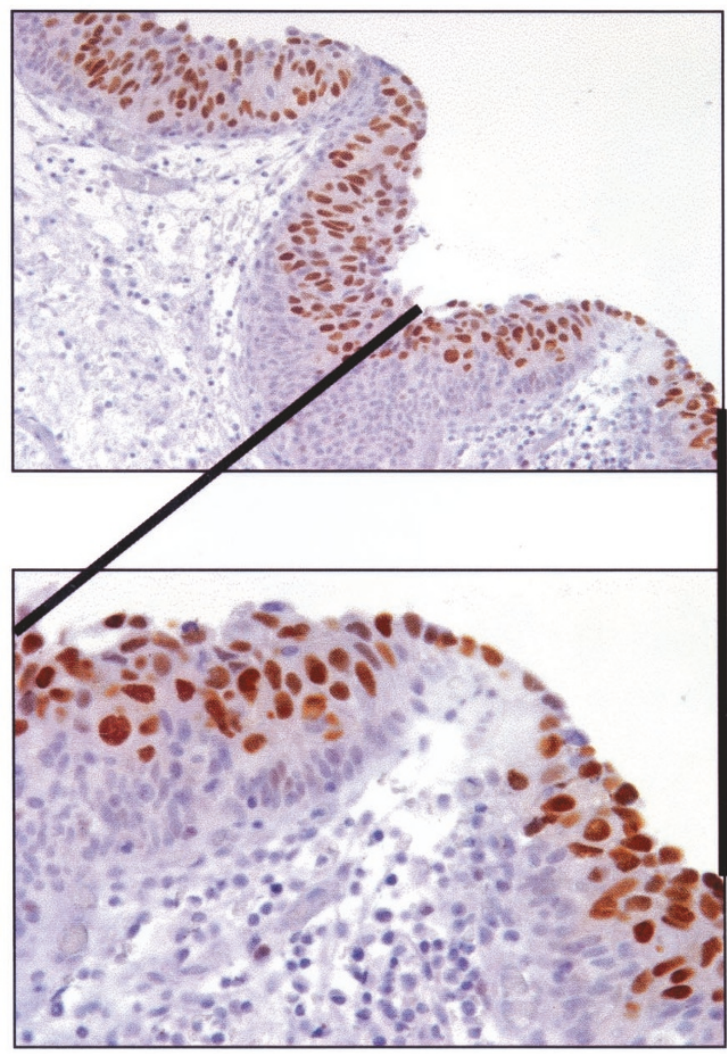

C

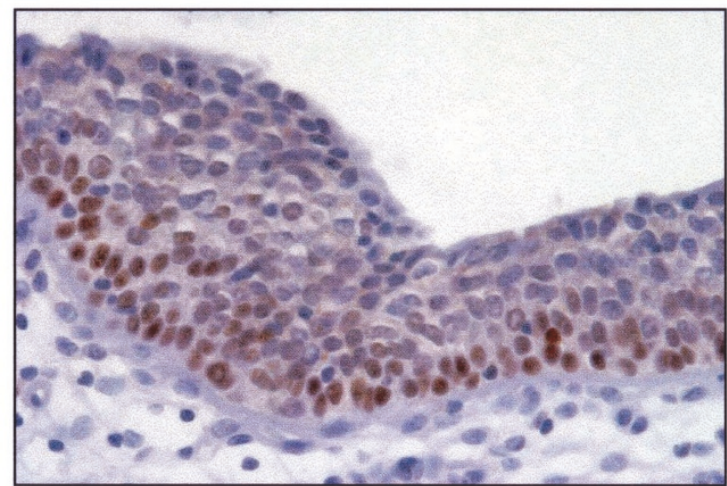

E

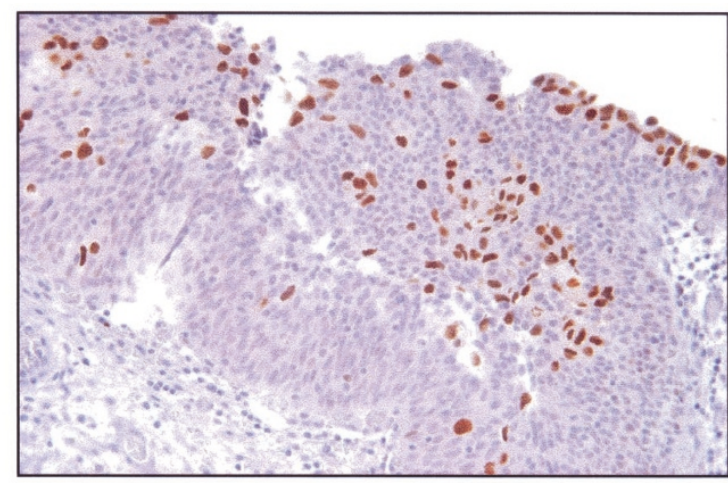

B

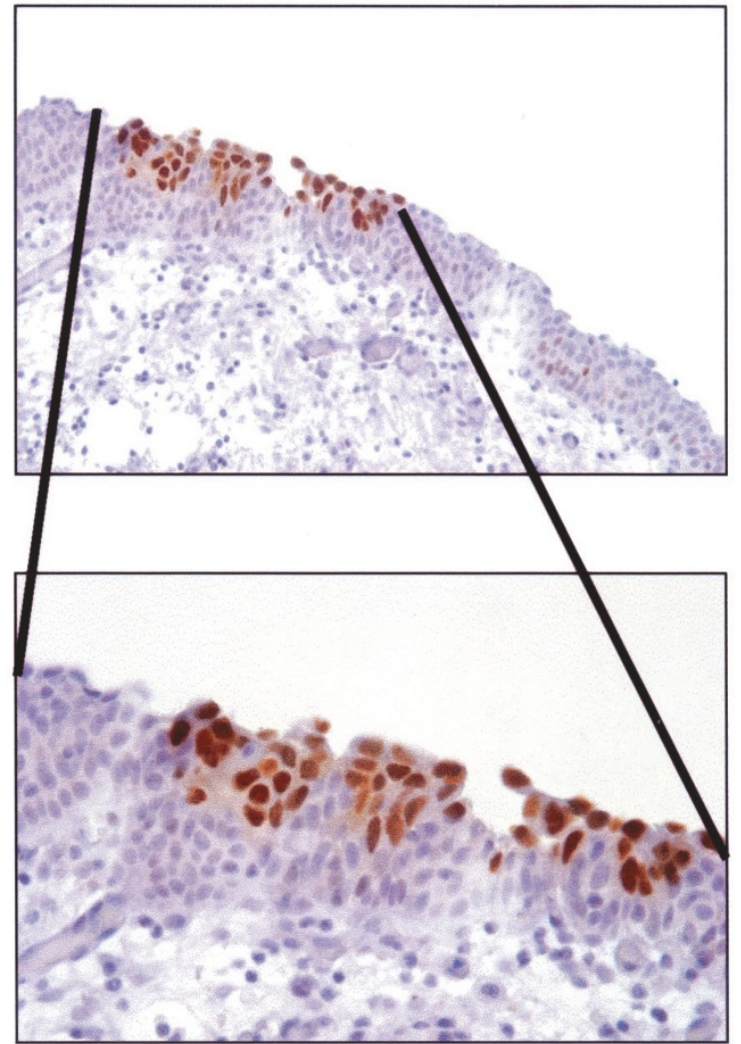

D

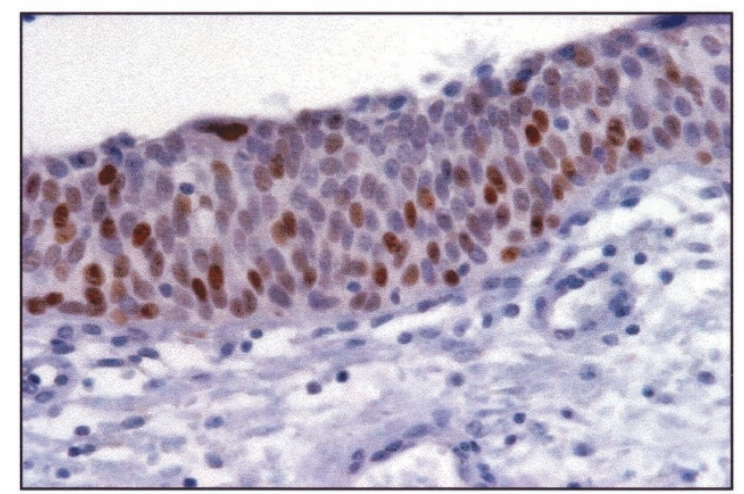

F

Figure 3.

Correlation of histopathology and immunohistochemical staining for p53. All lesions shown were positive in the PASA. A, Strong nuclear p53 staining in the poorly differentiated solid urothelial carcinoma from Patient 5 (sample 14). B, Hyperplastic urothelium with partial papillary growth, but without significant atypia from Patient 1 
detect a single or a few cells with abnormal p53. These cells can be the source of recurrences.

Dalbagni et al (2001) showed that several recurrent bladder tumors in one patient carried the identical p53-mutation, suggesting a clonal relationship. In another study (Hafner et al, 2001) of multifocal urothelial carcinomas located in both upper and lower urinary tract, up to 12 tumors revealed the identical mutation in the same patient. Genetic alterations in nonmalignant tissue samples are also reported from other multifocal and frequently recurrent tumor types. Tabor et al (2001) demonstrated areas of histologically normal mucosa with genetic alterations in a significant portion of patients with squamous cell carcinoma of the head and neck. In nonsmall cell lung cancer patients, Park et al (1999) found multiple clonal abnormalities in histologically normal bronchial epithelium.

Artificial tumor cell dissemination and contamination of the tissue samples both in situ during surgery or during preparation of the bladder specimens remains a possibility to explain our results. Such contamination may yield false-positive results when analyzed by a highly sensitive technique like PASA. However, our analyses showed regions of urothelium adjacent to or distant from the tumor without the mutation. Great care was taken to avoid contamination during specimen mapping and sectioning of the samples. Laserassisted microdissection (PALM) (Schutze and Lahr, 1998) yielded a highly pure cell population (>90\%) and minimized the risk of contamination. In one patient (Patient 3) the mutation was only found in the tumor but not in any other sample analyzed. In Patient 4 no residual tumor was seen histologically in the entire cystectomy specimen, but the p53 mutation from the tumor removed 2 months before cystectomy was detectable by PASA in many urothelial samples. Moreover, the detection of a p53 mutation in only one of the two separate tumors (Patient 1) makes contamination unlikely. Most significant is the strong correlation of PASA-positive samples with immunohistochemical results (Fig. 3), demonstrating that false results from contamination are rather unlikely.

In two cystectomy specimens, at least two different tumor clones were found. In Patient 1, only one of the two tumors showed a p53 mutation with widespread dissemination throughout the urothelium (Fig. 2A). In Patient 3, a papillary invasive tumor and CIS have been found, but only the papillary tumor showed a mutation (Fig. 2C). This mutation was not detectable in either CIS or any other urothelial sample by PASA. The appearance of oligoclonal tumors in two of five urinary bladders correlates with several other studies sug- gesting that more than one malignant tumor clone may develop in patients with urothelial carcinoma (Hafner et al, 2001; Hartmann et al, 2000, 2002; Paiss et al, 2002; Stoehr et al, 2000; Takahashi et al, 2001).

In four of five cases, widely spread patches containing cells with the p53 mutations were seen. These patches were found in regions of the bladder that were adjacent to the tumor, but also in distant urothelium. In all cases, the p53 mutant patches were in close proximity to each other, indicating a continuous tumor spread within the bladder. This finding favors an intraurothelial spread of tumor cells over intraluminal seeding, which would show a random distribution of PASA-positive areas with normal patches interspersed. Simon et al (2001) performed a cytogenetic analysis of six cystectomy specimens using $\mathrm{CGH}$ in combination with p53 sequence analysis and IHC. These authors found a close genetic relationship between all tumors and the surrounding uninvolved urothelium, supporting the concept of intraurothelial migration of the tumor cell clone. The widespread distribution of cells with genetic alterations in the urothelial field might be dependent on the p53 mutation of the tumor. This possibility needs to be studied by investigation of cystectomies with other than mutant p53 as target gene alterations.

Hafner et al (2001) found evidence for oligoclonality and tumor spread by intraluminal seeding in carcinomas of the upper and lower urinary tract by $\mathrm{LOH}$ analysis. All of their patients had at least one tumor in the upper and in the lower urinary tract, and the identical p53 mutations found can only be explained by a seeding mechanism. The frequent occurrence of p53-positive cells located at the luminal surface of normal or dysplastic urothelium detected in this study (Fig. 3, C to E) could be due to seeding of tumor cells and then by an intraurothelial outgrowth of the malignant clone.

In summary, we have demonstrated p53-mutant cells in normal or preneoplastic urothelial areas in patients with invasive bladder cancer, indicating extensive intraurothelial tumor cell spread. PASA for tracking specific p53 mutant clones is a very sensitive method for tumor cell detection. The excellent correlation of immunohistochemically positive urothelial patches and detection of a patient-specific p53 mutation supports the biologic significance of p53positive cells in the urothelium of tumor patients and supports the hypothesis of a clonal dissemination of a primary bladder carcinoma. PASA analysis could provide a very sensitive tool for detecting tumor recurrence in the urine of urothelial cancer patients.

(sample 22). Note the scattered p53-positive cells both near the surface and in lower portions of the urothelium. C, carcinoma in situ with pagetoid spread and strong nuclear positivity for p53 from Patient 5 (sample 4). D. Urothelial dysplasia. Luminal cells with nuclear irregularity and strong overexpression of the p53 protein from Patient 4 (sample 8). E, Normal urothelium and simple hyperplasia from Patient 4 (sample 18). Note the predominantly basal cells without atypia and nuclear staining for p53. F, Normal urothelium from Patient 1 (sample 30). There are no atypias and a normal maturation of the urothelium with superficial umbrella cells. p53 overexpression can be demonstrated in many cells throughout the urothelium. Original magnification, $A, B, C$, and $D$ upper panels, $\times 200$; $C$ and $D$, lower panels $E$ and $F, \times 400$. 


\section{Materials and Methods}

\section{Tissue Samples}

Fourteen cystectomy specimens from bladder cancer patients (seven men, seven women, mean age $65.8 \pm$ 4.6 years) were obtained directly from the operating room (Department of Urology, St. Josef Hospital, Regensburg, Germany). All patients gave informed consent for the study. The specimens were opened with a $Y$ incision by a pathologist. Tissue samples (size, approximately $1 \mathrm{~cm}^{2}$ ) were systematically dissected covering the entire urothelial lining. Samples were bisected and one half was snap frozen. The other half was formalinfixed for 24 hours and embedded in paraffin. The histopathologic diagnosis of the urothelial samples was rendered from both paraffin-embedded material and frozen tissue biopsies, and included staging (International Union Against Cancer, Geneva, Switzerland) (Sobin and Wittekind, 1997) and grading (World Health Organization, WHO) (Mostofi et al, 1999). Histologic mapping and genetic analysis were performed on corresponding lesions. All flat urothelial lesions were classified according to the new WHO classification of bladder tumors (Mostofi et al, 1999).

\section{DNA Isolation}

Sections $(5 \mu \mathrm{m})$ from frozen tissue samples were stained with methylene blue for approximately 15 seconds. Urothelial cells were collected using laser microdissection (PALM) (Schutze and Lahr, 1998) to obtain a purity of at least $90 \%$. Isolation of the DNA was performed as described previously (Hafner et al, 2001; Hartmann et al, 2000).

\section{Mutation Analysis of the p53 Gene}

Exons 5 to 9 of the p53 gene, containing more than $90 \%$ of all mutations found in malignancies (Hartmann et al, 1995; Levine, 1997), were analyzed using direct genomic sequencing. Analyses were performed using PCR primers and PCR conditions as described previously (Hafner et al, 2001). All mutations were verified by sequencing a second, independently generated PCR amplicon.

\section{PASA}

One microliter (approximately $100 \mathrm{ng}$ ) of the urothelial DNA was used for PCR amplifications. PASA primers and PCR conditions are shown in Table 1. All PCR reactions were run at a final volume of $25 \mu \mathrm{l}(0.2$ $\mathrm{mmol} / \mathrm{l}$ dNTP; $0.3 \mu \mathrm{mol} / \mathrm{l}$ primers; $1.5 \mathrm{mmol} / \mathrm{l} \mathrm{MgCl}_{2}$; 0.5 U Taq polymerase (Roche Diagnostics, Penzberg, Germany) in a PTC100 thermocycler (MJ Research, Watertown, Maryland). DNA from urothelial cell lines without p53 mutations served as negative controls and wild-type allele PCR was performed for each sample to ensure DNA quality. The specificity of each PASA reaction was tested independently three times. In case of insufficient amounts of DNA isolated from only a very small number of cells, a nested PASA was performed. The exon containing the mutation was amplified and used as a template for PASA. PCR products were separated through $1.5 \%$ agarose gels and visualized under ultraviolet light by using $0.05 \%$ ethidiumbromide.

\section{Immunohistochemical Staining}

An avidin-biotin peroxidase method with diaminobenzidine (DAB) was used on formalin-fixed, paraffinembedded material after incubation and microwave antigen retrieval. Frozen sections $(5 \mu \mathrm{m})$ were airdried, fixed in acetone, and IHC was performed in a NEXES Immuno Stainer (Ventana, Tucson, Arizona) following the manufacturer's instructions. The p53 antibody (sc-263, mouse monoclonal, recognizes both wild-type and mutant p53; Santa Cruz Biotechnology, Santa Cruz, California) was diluted 1:1000. Sections were counterstained with hematoxylin and embedded in Entellan mounting medium (EMS Diatome, Fort Washington, Pennsylvania). IHC analysis was performed by a researcher without knowledge of histopathologic or molecular data. P53 positivity in the primary tumor was defined as strong nuclear staining in at least $10 \%$ of the cells. A minimum of $1 \%$ of cells with strong nuclear staining was considered positive in all other urothelial samples.

\section{Acknowledgement}

We thank Ms. Andrea Schneider and Ms. Monika Kerscher for excellent technical assistance in tissue preparation, sequence analysis, and immunohistochemistry.

\section{References}

Baud E, Catilina P, Boiteux JP, and Bignon YJ (1998). Human bladder cancers and normal bladder mucosa present the same hot spot of heterozygous chromosome-9 deletion. Int $\mathrm{J}$ Cancer 77:821-824.

Boelker M (1996) Experimental limits of PCR analysis of $(C A)_{n}$ repeat alterations. Trends Genet 12:450-451.

Bottema CD and Sommer SS (1993). PCR amplification of specific alleles: rapid detection of known mutations and polymorphisms. Mutat Res 288:93-102.

Chaturvedi V, Li L, Hodges S, Johnston D, Ro JY, Logothetis C, von Eschenbach AC, Batsakis JG, and Czerniak B (1997). Superimposed histologic and genetic mapping of chromosome 17 alterations in human urinary bladder neoplasia. Oncogene 14:2059-2070.

Chow NH, Cairns P, Eisenberger CF, Schoenberg MP, Taylor DC, Epstein JI, and Sidransky D (2000). Papillary urothelial hyperplasia is a clonal precursor to papillary transitional cell bladder cancer. Int J Cancer 89:514-518.

Cordon-Cardo C, Cote RJ, and Sauter G (2000). Genetic and molecular markers of urothelial premalignancy and malignancy. Scand J Urol Nephrol Suppl 205:82-93.

Czerniak B, Chaturvedi V, Li L, Hodges S, Johnston D, Ro JY, Luthra R, Logothetis C, Eschenbach C, Grossman HB, Benedict W, and Batsakis JG (1999). Superimposed histologic and genetic mapping of chromosome 9 in progression of human urinary bladder neoplasia: Implications for a genetic model of 
multistep urothelial carcinogenesis and early detection of urinary bladder cancer. Oncogene 18:1185-1196.

Czerniak B, Li L, Chaturvedi V, Ro JY, Johnston DA, Hodges S, and Benedict WF (2000). Genetic modeling of human urinary bladder carcinogenesis. Genes Chromosom Cancer 27:392-402.

Dalbagni G, Ren ZP, Herr H, Cordon-Cardo C, and Reuter V (2001). Genetic alterations in TP53 in recurrent urothelial cancer: A longitudinal study. Clin Cancer Res 7:2797-2801.

Habuchi T, Takahashi R, Yamada H, Kakehi Y, Sugiyama T, and Yoshida O (1993). Metachronous multifocal development of urothelial cancers by intraluminal seeding. Lancet 342:1087-1088.

Hafner C, Knuechel R, Zanardo L, Dietmaier W, Blaszyk H, Cheville J, Hofstaedter F, and Hartmann A (2001). Evidence for oligoclonality and tumor spread by intraluminal seeding in multifocal urothelial carcinomas of the upper and lower urinary tract. Oncogene 20:4910-4915.

Hainaut P, Dogliotti E, Hernandez T, D'Errico M, and DeMarini DM (1998). Mutation spectra resulting from carcinogenic exposure: From model systems to cancer-related genes. Recent Results Cancer Res 154:97-127.

Hainaut P and Hollstein M (2000). p53 and human cancer: The first ten thousand mutations. Adv Cancer Res 77:81-137.

Harris AL and Neal DE (1992). Bladder cancer-field versus clonal origin (Editorial; comment). N Engl J Med 326:759-761.

Harris CC (1996). The 1995 Walter Hubert Lecturemolecular epidemiology of human cancer: insights from the mutational analysis of the p53 tumor-suppressor gene. $\mathrm{Br} \mathrm{J}$ Cancer 73:261-269.

Hartmann A, Blaszyk H, McGovern RM, Schroeder JJ, Cunningham J, De Vries EM, Kovach JS, and Sommer SS (1995). p53 gene mutations inside and outside exons 5-8: The patterns differ in breast and other cancers. Oncogene 10:681-688.

Hartmann A, Moser K, Kriegmair M, Hofstetter A, Hofstaedter $F$, and Knuechel $R$ (1999). Frequent genetic alterations in simple urothelial hyperplasias of the bladder in patients with papillary urothelial carcinoma. Am J Pathol 154:721-727.

Hartmann A, Rosner U, Schlake G, Dietmaier W, Zaak D, Hofstaedter F, and Knuechel R (2000). Clonality and genetic divergence in multifocal low-grade superficial urothelial carcinoma as determined by chromosome 9 and p53 deletion analysis. Lab Invest 80:709-718.

Hartmann A, Schlake G, Zaak D, Hungerhuber E, Hofstetter A, Hofstaedter F, and Knuchel R (2002). Occurrence of chromosome 9 and p53 alterations in multifocal dysplasia and carcinoma in situ of human urinary bladder. Cancer Res 62:809-818.

Koss LG (1979). Mapping of the urinary bladder: Its impact on the concepts of bladder cancer. Hum Pathol 10:533-548.

Kram A, Li L, Zhang RD, Yoon DS, Ro JY, Johnston D, Grossman HB, Scherer S, and Czerniak B (2001). Mapping and genome sequence analysis of chromosome 5 regions involved in bladder cancer progression. Lab Invest 81:1039-1048.

Levine AJ (1997). p53, the cellular gatekeeper for growth and division. Cell 88:323-331.

Mostofi FK, Davis CJJ, and Sesterhenn IA (1999). Histological typing of urinary bladder tumours. In: World Health Organization-International Histological Classification. Berlin: Springer.
Muto S, Horie S, Takahashi S, Tomita K, and Kitamura T (2000). Genetic and epigenetic alterations in normal bladder epithelium in patients with metachronous bladder cancer. Cancer Res 60:4021-4025.

Paiss T, Woehr G, Hautmann RE, Mattfeldt T, Mueller M, Haeussler J, and Vogel W (2002). Some tumors of the bladder are polyclonal in origin. J Urol 167:718-723.

Park IW, Wistuba II, Maitra A, Milchgrub S, Virmani AK, Minna JD, and Gazdar AF (1999). Multiple clonal abnormalities in the bronchial epithelium of patients with lung cancer. J Natl Cancer Inst 91:1863-1868.

Rossi MR, Masters JRW, Park S, Todd JH, Garrett SH, Sens MA, Somji S, Nath J, and Sens DA (2001). The immortalized UROtsa cell line as a potential cell culture model of human urothelium. Environ Health Perspect 109:801-808.

Schutze K and Lahr G (1998). Identification of expressed genes by laser-mediated manipulation of single cells. Nat Biotechnol 16:737-742.

Sidransky D, Frost P, Von Eschenbach A, Oyasu R, Preisinger AC, and Vogelstein B (1992). Clonal origin bladder cancer. N Engl J Med 326:737-740.

Simon R, Eltze E, Schaefer KL, Buerger H, Semjonow A, Hertle L, Dockhorn-Dworniczak B, Terpe HJ, and Boecker W (2001). Cytogenetic analysis of multifocal bladder cancer supports a monoclonal origin and intraepithelial spread of tumor cells. Cancer Res 61:355-362.

Simoneau M, Aboulkassim TO, LaRue H, Rousseau F, and Fradet $Y$ (1999). Four tumor suppressor loci on chromosome $9 q$ in bladder cancer: Evidence for two novel candidate regions at 9q22.3 and 9q31. Oncogene 18:157-163.

Slaughter DP, Southwick HW, and Smejkal W (1953). "Field cancerization" in oral stratified squamous epithelium. Clinical implications of multicentric origin. Cancer 6:963-968.

Sobin LH and Wittekind CH (1997). TNM classification of malignant tumours. Sobin $\mathrm{LH}$ and Wittekind $\mathrm{CH}$, editors. New York: Wiley-Liss, 187-194.

Spruck CH III, Ohneseit PF, Gonzalez-Zulueta M, Esrig D, Miyao N, Tsai YC, Lerner SP, Schmutte C, Yang AS, and Cote R (1994). Two molecular pathways to transitional cell carcinoma of the bladder. Cancer Res 54:784-788.

Stoehr R, Hartmann A, Hiendlmeyer E, Murle K, Wieland W, and Knuechel R (2000). Oligoclonality in early lesions of the urothelium as determined by microdissection-supported genetic analysis. Pathobiology 68:165-172.

Tabor MP, Brakenhoff RH, van Houten VMM, Kummer JA, Snel MHJ, Snijders PJF, Snow GB, Leemans CR, and Braakhuis BJM (2001). Persistence of genetically altered fields in head and neck cancer patients: Biological and clinical implications. Clin Cancer Res 7:1523-1532.

Takahashi T, Kakehi Y, Mitsumori K, Akao T, Terachi T, Kato T, Ogawa O, and Habuchi T (2001). Distinct microsatellite alterations in upper urinary tract tumors and subsequent bladder tumors. J Urol 165:672-677.

Yoon DS, Li L, Zhang RD, Kram A, Ro JY, Johnston D, Grossman HB, Scherer S, and Czerniak B (2001). Genetic mapping and DNA sequence-based analysis of deleted regions on chromosome 16 involved in progression of bladder cancer from occult preneoplastic conditions to invasive disease. Oncogene 20:5005-5014. 